\title{
Investigation of microwave sensor and integrate with polydimethylsiloxane for medical imaging application
}

\author{
Nurhasniza Edward', Lavanya Paramasivam², Zahriladha Zakaria ${ }^{3}$, Amyrul Azuan Mohd Bahar ${ }^{4}$ \\ ${ }^{1,2,3}$ Centre for Telecommunication Research and Innovation (CeTRI), Fakulti Kejuruteraan Elektronik dan Kejuruteraan \\ Komputer (FKEKK), Universiti Teknikal Malaysia Melaka (UTeM), Melaka, Malaysia \\ ${ }^{4}$ Intel Microelectronics, Bayan Lepas Free Industrial Zone, Bayan Lepas, Malaysia
}

\begin{tabular}{l} 
Article Info \\
\hline Article history: \\
Received May 27, 2021 \\
Revised Sep 16, 2021 \\
Accepted Sep 21, 2021 \\
\hline
\end{tabular}

\section{Keywords:}

Medical imaging application polydimethylsiloxane Wearable antenna Wideband frequency

\begin{abstract}
The small-sized wideband antenna is one of the antennas used in the medical field to detect body tissue. The antenna's direct contact with the human body causes reflected signal due to the high body coupling, and the narrower bandwidth tends to reduce the data transfer rate in transmission. Therefore, this paper aims to design a wideband antenna with wearable properties operated in the frequency range of $3 \mathrm{GHz}$ to $6 \mathrm{GHz}$. The antenna is designed with a rectangular-shaped patch with notches and the t-slot shaped partial slot ground. The connected speech test (CST) studio suite software is used to design and optimize the miniature antenna, which measures $24 \mathrm{~mm}(\mathrm{~W})$ x $38 \mathrm{~mm}(\mathrm{~L})$ x $0.168 \mathrm{~mm}(\mathrm{H})$. The antenna is then embedded with polydimethylsilixane (PDMS) at the top half of the antenna with the dimension $24 \mathrm{~mm}(\mathrm{~W}) \times 19 \mathrm{~mm}$ (L) $x 1 \mathrm{~mm}(\mathrm{H})$ and also fully occupied. The antenna is configured with the bending capabilities to adapt the human body surface at an angle of $30^{\circ}$. The antenna is having the benefits of small size, cost-effective, and easy to fabricate. The antenna design can effectively detect unusual body tissue, and it safe to be used.
\end{abstract}

This is an open access article under the CC BY-SA license.

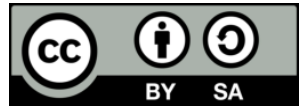

\section{Corresponding Author:}

Zahriladha Zakaria

Centre for Telecommunication Research \& Innovation (CeTRI)

Fakulti Kejuruteraan Elektronik dan Kejuruteraan Komputer (FKEKK)

Universiti Teknikal Malaysia Melaka (UTeM)

Hang Tuah Jaya, 76100 Durian Tunggal, Melaka, Malaysia

Email: zahriladha@utem.edu.my

\section{INTRODUCTION}

The medical field is continually upgrading by the newest technology as parallel to the complications of the health disease that internally veined. Relating to the internal human body complexities, the medical imaging application developed using microwave transmission. Microwave imaging (MWI) is a fast-growing technique in medical research studies. It is a promising rising modality that employs low-power microwave waveforms focused on the physique and generate photographs of the body by using the resultant backscattered signals. MWI is based on improving dielectric properties: permittivity and material conductivity [1].

In biomedical applications, MWI has elevated interests. It is extra attractive, mainly its non-ionizing and non-invasive, being the depth of penetration in the human tissue life like ample that approves to obtain excessive-decision images compared to conventional imaging modalities such as X-ray mammography. As for microwave imaging, for example, opposite to computed tomography (CT), microwaves are no longer ionized consequently do now not possess damage to the human body. Microwave imaging can be developed at a fraction of the cost for magnetic resonance imaging (MRI) or CT facility. It does not need a display 
screen room and can be used in IC gadgets or ambulances due to its compact nature. A predominant problem going through in microwave imaging is the reflection of electricity from the skin, which may also have large magnitude orders than the reflected tumor response. Thus, researchers have conducted advanced research to investigate the performance efficiency of antennas by using various wearable materials and different dielectric constant substrates to develop the medical imaging application.

Wearable microstrip wideband antenna is one of the most intriguing tools in a microwave imaging application, considering the wearable element and covering the operating frequency of $1.6 \mathrm{GHz}$ to $11.2 \mathrm{GHz}$ [2][6], which bandwidth at least of $2 \mathrm{GHz}$ or more. Hence, the wideband antenna with a frequency range of $3 \mathrm{GHz}$ to $6 \mathrm{GHz}$ and flexible and wearable properties is developed by polydimethylsiloxane (PDMS). The PDMS is a polymer gel designed with a fragile substrate. It acts as a spacer between the antenna and the human body to reduce signal loss and avoid direct connectivity between the human body and the antenna [7]-[10]. It also protects the antenna for a longer life span, whereas the wideband allows a higher rate of transmission and emits low radiation.

The microstrip antenna had chosen among the others, as it allows easy fabrication, designation increase in the gain, directivity, and flexibility [3], [11], [12]. The antenna design can efficiently discover abnormal body tissue, and it is secure to be used [13]-[15]. The antenna cannot carry an unhealthy effect on the physique used in transmitting data signals only. The antenna design is anticipated to have a frequency range in wideband, and it can be used all over the human body [16]-[18]. The antenna is designed for medical application and can become aware of unusual tissue like most cancers and tumor-affected tissues [19], [20]. As the antenna is wearable, it is safe to use and environmentally friendly.

The foundation of an antenna is used to transmit or receive the data signal in an electromagnetic wave. In other words, the antenna is the electromagnetic transducer that converts the electrical power to electromagnetic waves or vice versa within a transmission line to radiate in free-space during transmitting mode or convert freespace waves to guided waves during receiving mode [21]. Electromagnetic waves are often referred to as radio waves. Bandwidth is proportional to the operating frequency, which is also bandwidth percentage. If bandwidth is demonstrated in absolute frequency units, it will vary depending on the center frequency.

The return loss is another method of describing misalignment. The return loss is generally referred to as S11, and the return loss is the power reflected from the transmitting antenna. An antenna transmits the electromagnetic wave to the target area, but some signal is ignored, and it must pass back to the antenna. S11 is also referred to as the coefficient of reflection since it indicates the reflected power value. Antenna gain is a performance measure, which combines the directivity of an antenna with electrical efficiency. The definition of the gain is the ratio of its directional radiation intensity to the intensity of the radiation. The radiation pattern of an antenna is a graphical representation of radiation properties that determines the directivity of an antenna [22]. The directivity of the antenna is used to focus the radiation beam in the desired direction. Conversely, the antenna should be radiating equally in all directions in a dynamic device where the transceiver is not set, which is known as an omnidirectional antenna.

A literature review has proposed the semi-flexible wideband antenna for biomedical telemetry applications with an overall dimension of $17 \mathrm{~mm} \times 25 \mathrm{~mm} \times 0.787 \mathrm{~mm} \mathrm{[16].} \mathrm{The} \mathrm{antenna} \mathrm{is} \mathrm{given} \mathrm{a}$ rectangular patch with the slots' additions then modified with partial ground plane to improve the operational frequency of $1.5 \mathrm{GHz}$ to $3 \mathrm{GHz}$. It sustains $2.50 \mathrm{~dB}$, high gain at $2.4 \mathrm{GHz}$, and serves good performance for on-body communication as had tested on proximity of the human body. The bandwidth has been increased using a hook-shaped stub resonator with the ground plane. A wideband rectangular and circular ring-shaped patch antenna with gap coupled meandered parasitic elements designed for wireless application [23]. The projects carried many operational frequency ranges of $1.26-1.36 \mathrm{GHz}, 1.83-3.81 \mathrm{GHz}, 7.6-7.85 \mathrm{GHz}, 9.6-$ 10.74 GHz, 13.58-14.23 GHz with wireless local area network (WLAN), worldwide interoperability for microwave access (WiMAX), $\mathrm{C}$, and $\mathrm{X}$ band applications.

A flexible wideband antenna using PDMS composite substrate characterization is conducted. The conductive fibers are used to build metallic parts on the PDMS. It is providing good performance in comparison to their conventional dielectric at higher frequencies [24].

L-shape fed microstrip patch antenna, wideband range backed by the conductor plane purposed. L-shaped fed relies on the proximity coupling scheme to encourage radiation in free space and on-body at the $2.45 \mathrm{GHz}$ industrial, scientific and medical (ISM) band [3]. The The L-shape feed is used to overcome the compact structure's impedance mismatch. The conductor plane function as a reflector is placed $2 \mathrm{~mm}$ away from the antenna to minimize the backward radiation to the human body; the distance lesser than the $2 \mathrm{~mm}$ will affect the antenna's gain, which means low gain value. The wide impedance bandwidth and the radiation patterns unconcerned and meet the requirement of internet of things (IoT) wearable sensors.

The antenna to consider the wearable properties depends on the substrate used to patch on the human body. The PDMS effects and results are tested in many microstrip patch antenna projects [16], [21]. The wearable antenna characteristic is also discussed for future developments according to the application by determining the performances [25]. 
PDMS is known as a material that potent to use is subject to the wearable and flexible antenna. According to a research study [8], an antenna is fabricated with copper foil on PDMS substrate. The copper acts as a radiating element and able to hold mechanical strains. The antenna design has values of 2.7 relative permittivity at $5.8 \mathrm{GHz}$. The loss tangent found is 0.013 relatively obtain good return loss and radiation pattern.

Therefore, a wideband antenna with wearable properties operated in the frequency range of $3 \mathrm{GHz}$ to $6 \mathrm{GHz}$ is proposed in this paper. The antenna is designed with a rectangular-shaped patch with notches and the t-slot shaped partial slot ground. The method used for bandwidth enlargement is rectangular patch configuration design with slots. A t-slot is applied on the base plane for the same purpose and increase performance on high frequency as the addition of the notches and staircase.

\section{RESEARCH METHOD}

A rectangular patch antenna with the partial ground is designed. The antenna design with dimensions in Table 1 is illustrated in Figure 1. The antenna patch is modified to increase the bandwidth by adding notches. High frequency slots were operated, and ripples were introduced. A t-shaped notch is introduced for the partial ground to increase the antenna's bandwidth. The t-shaped slot has a high frequency operation. Roger Duroid 4350 B is used as a substrate of the antenna with a thickness of $0.168 \mathrm{~mm}, 3.48$ permittivity, and a tangent loss of 0.0037 . The substrate is chosen due to its low loss, market availability, and very small thickness. The antenna size of a miniature antenna is $38 \mathrm{~mm}(\mathrm{~L}) \times 24 \mathrm{~mm}(\mathrm{~W}) \times 0.168 \mathrm{~mm}(\mathrm{H})$.

Table 1. Dimension of the antenna

\begin{tabular}{lccc}
\hline \multicolumn{1}{c}{ Symbol } & Value $(\mathrm{mm})$ & Symbol & Value $(\mathrm{mm})$ \\
\hline Length of patch, La & 11.7 & W2 & 1 \\
Width of patch, W & 16 & W3 & 0.8 \\
Length of feedline, $y_{0}$ & 20.8 & W4 & 0.65 \\
Length of substrate & 28 & L1 & 1 \\
Width of substrate & 24 & L2 & 1 \\
Ground length & 20 & L3 & 1 \\
Feedline width & 0.8 & L4 & 0.5 \\
W1 & 1.2 & L5 & 1.3 \\
Length of substrate & 28 & L1 & 1 \\
\hline
\end{tabular}
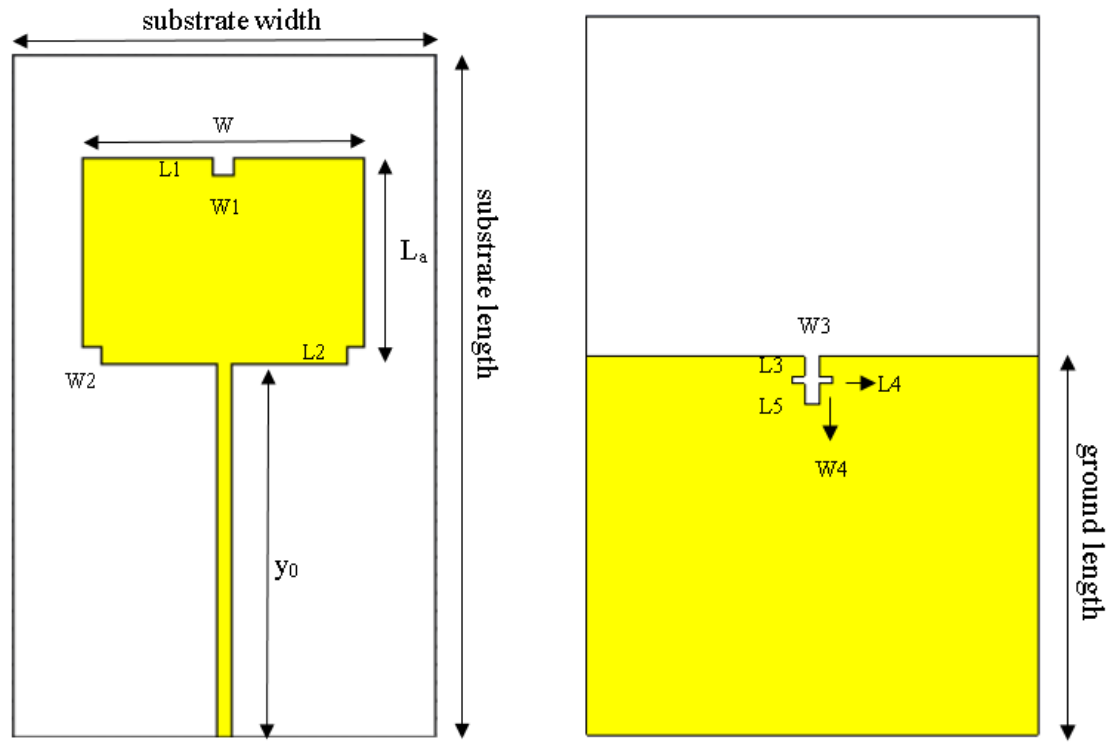

Figure 1. Front and back view of the antenna

The antenna is designed in the CST Software in advance for the modified purpose. The S-parameter of the antenna is the primary concern of the antenna, and the reflection coefficient of better than $10 \mathrm{~dB}$ is taken into account. The S-parameter for simulated antenna from $3 \mathrm{GHz}$ to $6 \mathrm{GHz}$ is depicted in Figure 2. The radiation pattern is on the E-plane of the antenna shows the omnidirectional antenna in Figure 3, and the highest gain is $6.731 \mathrm{~dB}$ at $6 \mathrm{GHz}$. 


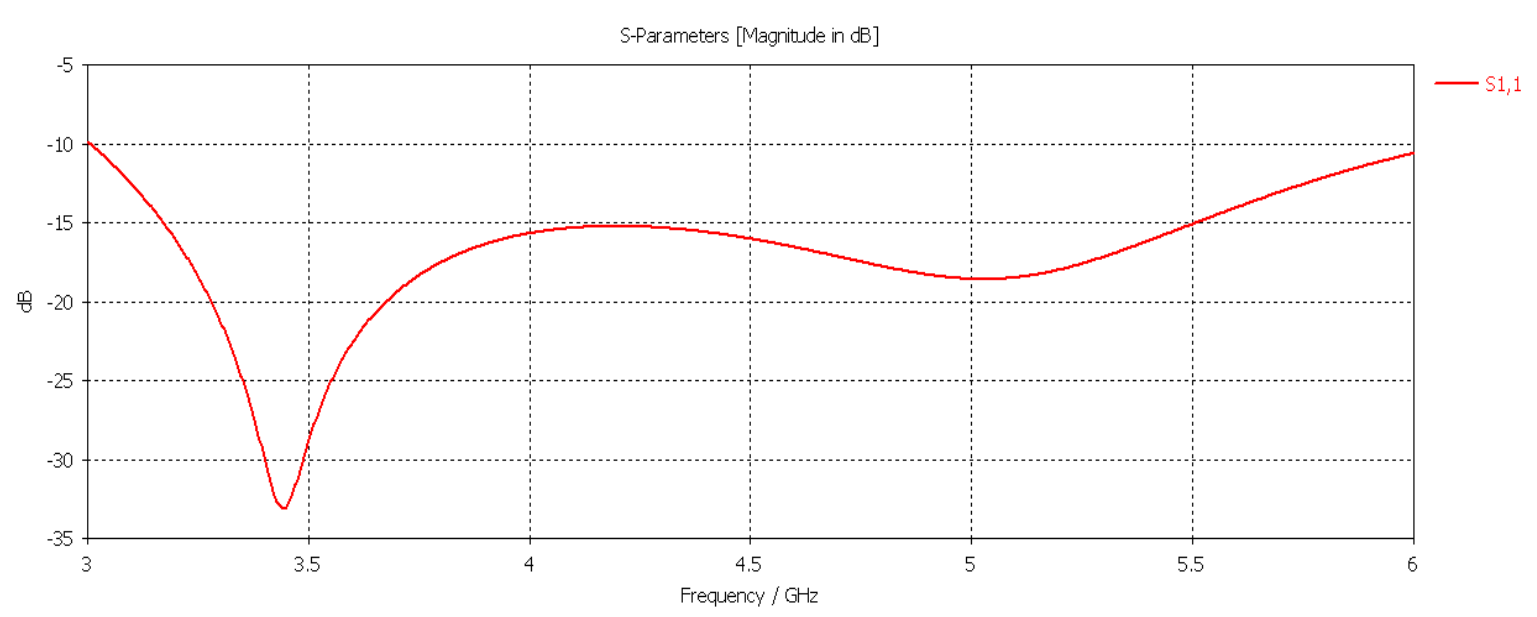

Figure 2. Return loss waveform

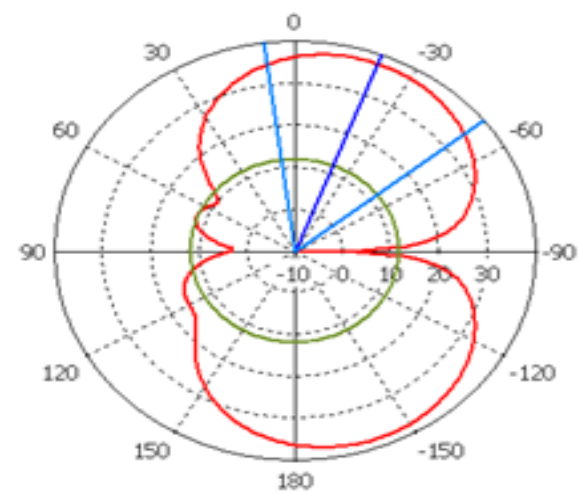

Figure 3. Radiation pattern at $6 \mathrm{GHz}$

The antenna configurations are designed. The specifications such as bandwidth, frequency range, and patch antenna can indeed be set for antenna prefix. The permittivity and thickness of the substrate are essential for the design of the antenna. The material used as a substrate is supposed to be Roger Duroid 4350 B. The material is chosen based on its durability and is commercially available. The project seeks to expand the antenna with the correct functional capability in technical configuration at this point. The physical formation of the antenna needs to be somehow calibrated and configured for a satisfactory response.

\section{POLYDIMETHYLSILOXANE INTEGRATION}

The antenna is embedded with PDMS, and the response of the antenna is simulated and measured. PDMS is having the dielectric constant, $\varepsilon$ r of 2.7, and the dissipation factor, $\tan \sigma$ of 0.009 . Half PDMS and full PDMS are integrated with the antenna. Half PDMS antenna is only covered on the top half of the antenna. The PDMS is only integrated on the patch. The dimension of the PDMS on the antenna is $24 \mathrm{~mm}$ (W) $x 19 \mathrm{~mm}(\mathrm{~L}) \times 1 \mathrm{~mm}(\mathrm{H})$. The antenna with full PDMS is fully covered on the top of the antenna with 24 $\mathrm{mm}(\mathrm{W}) \times 38 \mathrm{~mm}(\mathrm{~L}) \times 1.168 \mathrm{~mm}(\mathrm{H})$. Figure 4 shows the antenna with half PDMS and full PDMS embedded. PDMS integration on the top antenna is the substrate material used as a spacer to protect the antenna. The bending of the antenna verification takes place with and without PDMS to analyze the flexibility outcome of the antenna.

The simulation results are compared with and without PDMS in the antenna. The effect of PDMS is the waveform shift to the left based on Figure 5. The low frequency's return loss is reduced while at high frequency is improved. Based on Figure 6, the radiation of the antenna shows for half PDMS and full PDMS integration at $4.5 \mathrm{GHz}$, respectively. The gain shows a rise in the gain for PDMS integration at the $4.5 \mathrm{GHz}$ as well. The radiation pattern of the antenna shows it is an omnidirectional antenna. 

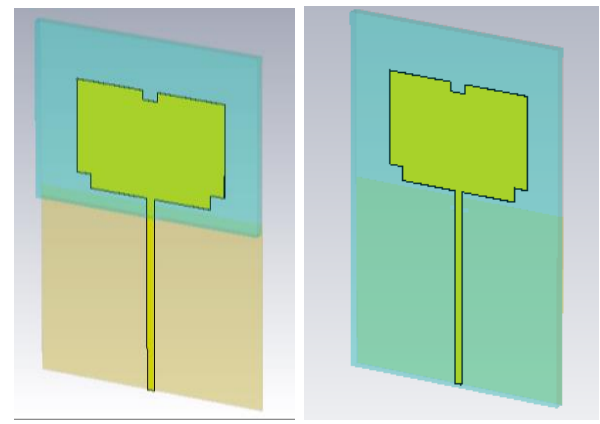

Figure 4. Hall and full PDMS antenna

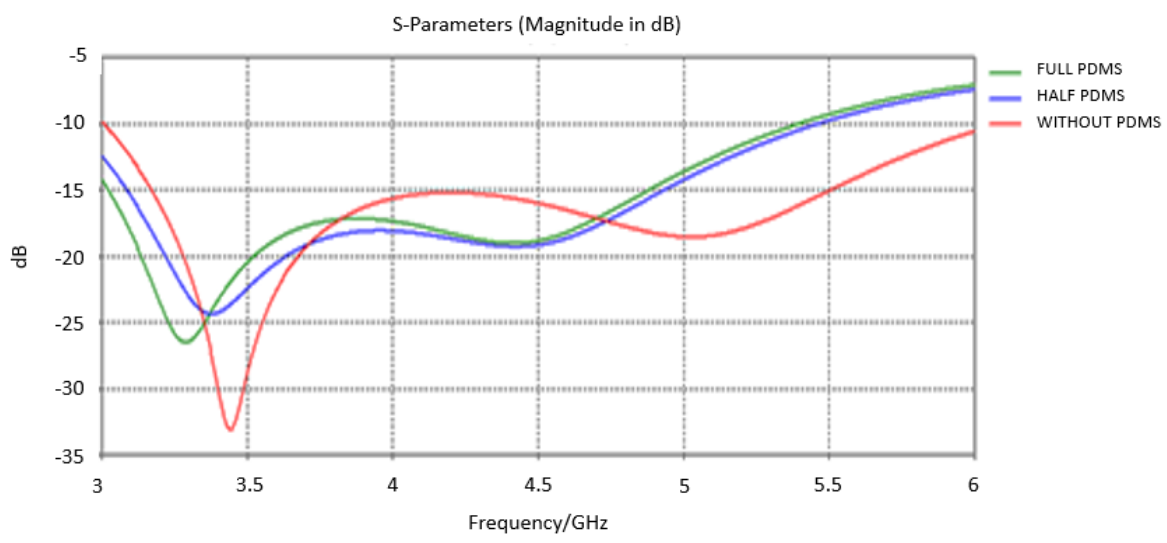

Figure 5. Comparison of the antenna for return loss parameter
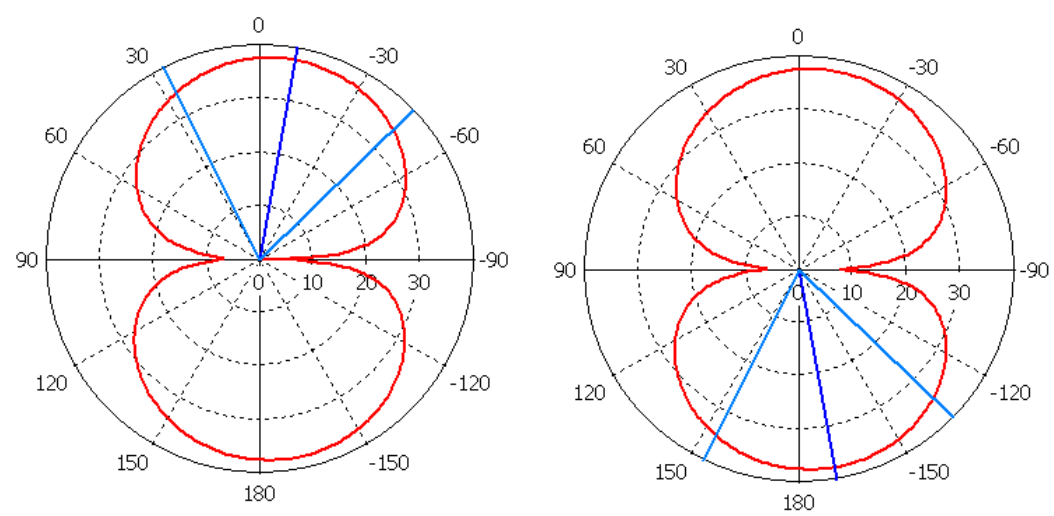

Figure 6. Comparison of the radiation pattern of antenna

The overall gain between the antennas is similar. However, as shown in Table 2, it differs between the antennas at a specific frequency. The antennas' gain in PDMS is low at $6 \mathrm{GHz}$, as the antenna's return loss is reduced. The full PDMS antenna has a gain of $6,183 \mathrm{dBi}$ at $6 \mathrm{GHz}$, lower than the other antennas because of an antenna bandwidth reduction with full PDMS.

Table 2. Comparison between antenna for gain parameter

\begin{tabular}{cccc}
\hline Frequency $(\mathrm{GHz})$ & \multicolumn{3}{c}{ Gain $(\mathrm{dB})$} \\
& Without PDMS & Half PDMS & FULL PDMS \\
\hline 3 & 4.943 & 5.162 & 5.286 \\
4.5 & 6.662 & 6.704 & 6.730 \\
6 & 6.731 & 6.252 & 6.183 \\
\hline
\end{tabular}




\section{FLEXIBLE CONFIGURATION}

The antenna is then carried with bending configuration by certain angles. The response of the antenna is simulated and observed for the ability to adapt to the human body. The bending of the antenna implemented vertically at both sides for full PDMS and half PDMS antenna, as shown in Figure 7. The configuration is made by converting the antenna's solid property to a sheet and simulating bend shape by degree method.

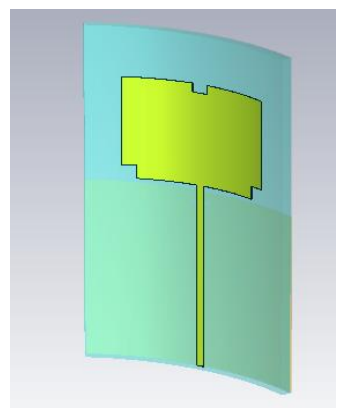

(a)

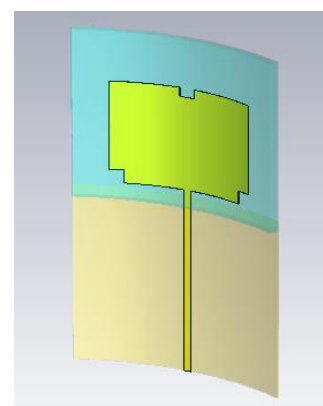

(b)

Figure 7. These figure are; (a) Full PDMS, (b) half PDMS antenna bending at the angle of $30^{\circ}$

The S-parameter of the antenna bending that configured at the angle of $30^{\circ}$ shows in Figure 8 . The reflection coefficient of better than $10 \mathrm{~dB}$ is counted; thus, $0.4 \mathrm{GHz}$ shrinkage of the operational bandwidth is observed at a lower frequency, $3 \mathrm{GHz}$. The bandwidth is analyzed from the return loss factor; $2.6 \mathrm{GHz}$ of frequency bandwidth is attained and shows $55.32 \%$ of the bandwidth percentage, which lies in the wideband range. The percentage of the bandwidth of the flexible PDMS antenna possesses low value than the antenna without bending configuration. The full PDMS and half PDMS antenna share a similar response as the antenna without PDMS.

The radiation pattern for half and full antenna PDMS shows a similar pattern. The antenna's radiation pattern is on the E-plane and it is an omnidirectional antenna. The gain increases as the frequency increase and the peak gain at $6 \mathrm{GHz}$ is $6.002 \mathrm{~dB}$ for antenna without PDMS, $7.113 \mathrm{~dB}$ for half PDMS antenna, and $7.106 \mathrm{~dB}$ for full PDMS antenna. The overall gain is acceptable as the values are positive. The overall gain is tabulated and compared with the previous results, as shown in Table 3.

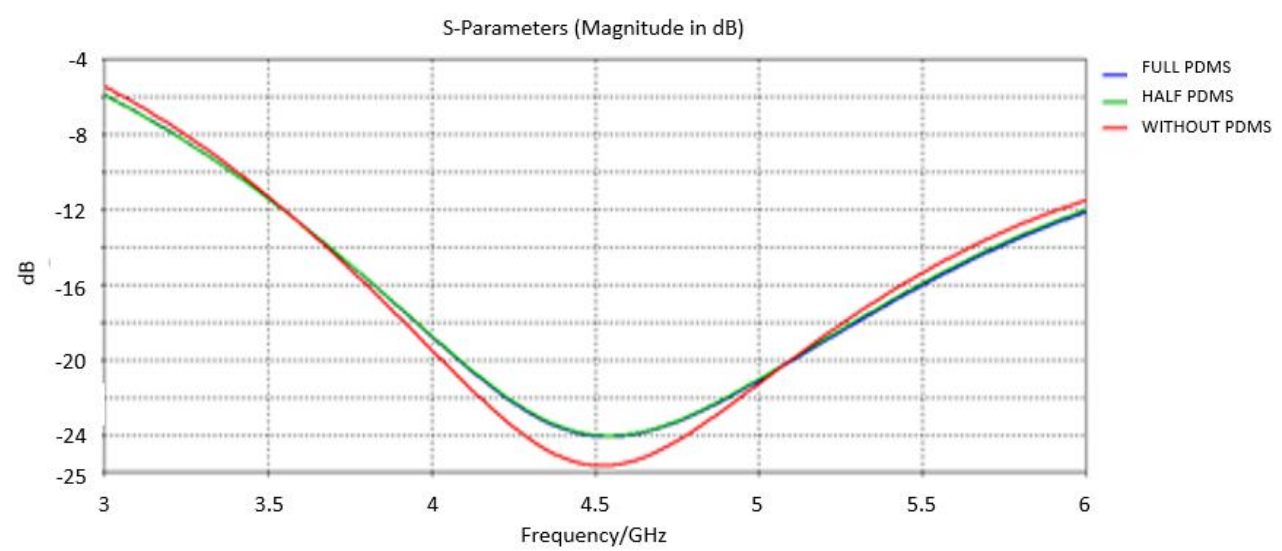

Figure 8. S-parameter results of the antenna

Table 3. Comparison of simulated gain of antenna for PDMS integration and bending configuration

\begin{tabular}{ccccccc}
\hline Frequency (GHz) & \multicolumn{2}{c}{ Without PDMS } & \multicolumn{2}{c}{ HALF PDMS } & \multicolumn{2}{c}{ FULL PDMS } \\
DEGREE & $0^{\circ}$ & $30^{\circ}$ & $0^{\circ}$ & $30^{\circ}$ & $0^{\circ}$ & $30^{\circ}$ \\
\hline 3.0 & 4.943 & 3.048 & 5.286 & 4.026 & 5.162 & 4.029 \\
4.5 & 6.662 & 5.716 & 6.730 & 6.671 & 6.704 & 6.671 \\
6.0 & 6.731 & 6.002 & 6.183 & 7.113 & 6.252 & 7.106 \\
\hline
\end{tabular}




\section{CONCLUSION}

The wideband antenna is thoroughly investigated for medical applications with the aid of PDMS. The antenna is modeled with partial ground. The method used to increase the antenna's operational frequency is rectangular patch configuration design with slots for bandwidth enlargement. A t-slot is applied on the base plane for the same purpose, performance on high frequency as the addition of the notches and staircase. Frequency also increases the number of ripples as the notch increases. As a culmination of the antenna design with an overall dimension of $24 \mathrm{~mm}(\mathrm{~W}) \times 38 \mathrm{~mm}(\mathrm{~L})$ x $0.168 \mathrm{~mm}(\mathrm{H})$ developed on Rogers Duroid $4350 \mathrm{~B}$ with 3.48 dielectric constant. The simulation illustrates that the antenna with a partial ground, wide bandwidth and omnidirectional antenna attained. The antenna is then integrated with PDMS to introduce the wearable properties. The PDMS-embedded antennas are differentiated into half PDMS and full PDMS. MPart of the PDMS is shielded on the antenna with the top half with $24 \mathrm{~mm}(\mathrm{~W}) \times 19 \mathrm{~mm}(\mathrm{~L}) \times 1 \mathrm{~mm}(\mathrm{H})$ dimension, while the full PDMS antenna is the antenna covers $24 \mathrm{~mm}(\mathrm{~W}) \times 38 \mathrm{~mm}(\mathrm{~L}) \times 1 \mathrm{~mm}(\mathrm{~W}) \times 1 \mathrm{~mm}$ PDMS (H). The PDMS application expands the antenna thickness by $1 \mathrm{~mm}$. Half-PDMS antenna with a simulated result with a bandwidth of $3 \mathrm{GHz} 5.47 \mathrm{GHz}$, while the full PDMS antenna has a bandwidth of 3 $\mathrm{GHz}$ to $5.4 \mathrm{GHz}$. The PDMS antenna reduces the operational bandwidth of the initial antenna.

The antenna is, indeed, secured by the PDMS as a wearable property antenna. The antenna incorporated with PDMS is effectively accounted for by this analytic project. Respect to the design theory and concepts were successfully presented with the simulation results. This initiative was limited to the wideband medical aid antenna. There are several viable accomplishments to the field of research practice in which for future progress. This research is carried out on a rectangular shaped patch with a partial field structure, and studies can be examined on a one-way antenna with a full ground plane for better directivity and gain. Besides, the antenna can be connected to some versatile antenna properties, which allow it to be used on any part of the body and patchable. Antenna with flexible enhancement properties is impotent in the medical application for quicker scattered accumulation. Even more, research can be done on the frequency spectrum of the ultra-wide band (UWB). The lower section of the UWB frequency spectrum offers greater penetration, while the higher part allows better image resolution. The antenna which operates in the UWB can penetrate the signal into the human body and model the resolution of the picture that in place. Finally, the antenna for medical applications can technically be used for unique cases of tissue detection. The antenna can reconstruct the image from the scattered image signal and sense the location of the irregular tissue.

\section{ACKNOWLEDGEMENTS}

We are grateful to Universiti Teknikal Malaysia Melaka (UTeM) under the Zamalah Scheme for their encouragement and help in supporting financially to complete this research work.

\section{REFERENCES}

[1] A. H. Golnabi, P. M. Meaney, S. Geimer, and K. D. Paulsen, "Microwave imaging for breast cancer detection and therapy monitoring," 2011 IEEE Topical Conference on Biomedical Wireless Technologies, Networks, and Sensing Systems, 2011, pp. 59-62, doi: 10.1109/BIOWIRELESS.2011.5724347.

[2] X. Lin, Y. Chen, Z. Gong, B. Seet, L. Huang, and Y. Lu, "Ultrawideband Textile Antenna for Wearable Microwave Medical Imaging Applications," in IEEE Transactions on Antennas and Propagation, vol. 68, no. 6, pp. 4238-4249, June 2020, doi: 10.1109/TAP.2020.2970072.

[3] C. E. Guan and T. Fujimoto, "Design of a Wideband L-Shape Fed Microstrip Patch Antenna Backed by Conductor Plane for Medical Body Area Network," Electronics, vol. 9, no. 1, p. 21, 2020, doi: 10.3390/electronics9010021.

[4] A. S. M. Alqadami and M. F. Jamlos, "Design and development of a flexible and elastic UWB wearable antenna on PDMS substrate," 2014 IEEE Asia-Pacific Conference on Applied Electromagnetics (APACE), 2014, pp. 27-30, doi: 10.1109/APACE.2014.7043799.

[5] R. B. V. B. Simorangkir, A. Kiourti, and K. P. Esselle, "UWB Wearable Antenna With a Full Ground Plane Based on PDMS-Embedded Conductive Fabric," in IEEE Antennas and Wireless Propagation Letters, vol. 17, no. 3, pp. 493-496, March 2018, doi: 10.1109/LAWP.2018.2797251.

[6] L. A. Yimdjo Poffelie, P. J. Soh, S. Yan, and G. A. E. Vandenbosch, "A High-Fidelity All-Textile UWB Antenna With Low Back Radiation for Off-Body WBAN Applications," in IEEE Transactions on Antennas and Propagation, vol. 64, no. 2, pp. 757-760, February 2016, doi: 10.1109/TAP.2015.2510035.

[7] K. Guido and A. Kiourti, "Wireless Wearables and Implants: A Dosimetry Review," Bioelectromagnetics, vol. 41, no. 1, pp. 3-20, December 2019, doi: 10.1002/bem.22240

[8] B. Mohamadzade, R. M. Hashmi, R. B. V. B. Simorangkir, R. Gharaei, S Ur Rehman, and Q. H. Abbasi, "Recent Advances in Fabrication Methods for Flexible Antennas in Wearable Devices: State of the Art," Sensors, vol. 19, no. 10, p. 2312, May 2019, doi: 10.3390/s19102312.

[9] A. Y. I. Ashap et al., "Flexible Wearable Antenna on Electromagnetic Band Gap using PDMS substrate," TELKOMNIKA Telecommunication, Computing, Electronics and Control, vol. 15, no. 3, pp. 1454-1460, Sept 2017, doi: 10.12928/telkomnika.v15i3.7214. 
[10] D. K. Janapala, M. Nesasudha, T. M. Neebha, and R. Kumar, "Flexible PDMS Antenna Backed with Metasurface for 2.4GHz Wearable Applications," 2019 IEEE 1st International Conference on Energy, Systems and Information Processing (ICESIP), 2019, pp. 1-3, doi: 10.1109/ICESIP46348.2019.8938235.

[11] F. Alsharif and C. Kurnaz, "Wearable Microstrip Patch Ultra Wide Band Antenna for Breast Cancer Detection," in 201841 st International Conference on Telecommunications and Signal Processing (TSP), 2018, pp. 1-5, doi: 10.1109/TSP.2018.8441335.

[12] R. Inum, M. M. Rana, and M. A. Quader, "Modeling of an efficient microstrip patch antenna for microwave brain imaging system," $20163 \mathrm{rd}$ International Conference on Electrical Engineering and Information Communication Technology (ICEEICT), 2016, pp. 1-6, doi: 10.1109/CEEICT.2016.7873118.

[13] A. Y. I. Ashyap et al., "An Overview of Electromagnetic Band-Gap Integrated Wearable Antennas," in IEEE Access, vol. 8, pp. 7641-7658, 2020, doi: 10.1109/ACCESS.2020.2963997.

[14] R. B. V. B. Simorangkir, Y. Yang, L. Matekovits, and K. P. Esselle, "Dual-Band Dual-Mode Textile Antenna on PDMS Substrate for Body-Centric Communications," in IEEE Antennas and Wireless Propagation Letters, vol. 16, pp. 677-680, 2017, doi: 10.1109/LAWP.2016.2598729.

[15] M. N. Ramli et al., "SAR for wearable antennas with AMC made using PDMS and textiles," 2017 XXXIInd General Assembly and Scientific Symposium of the International Union of Radio Science (URSI GASS), 2017, pp. 1-3, doi: 10.23919/URSIGASS.2017.8105353.

[16] A. Smida, A. Iqbal, A. J. Alazemi, M. I. Waly, R. Ghayoula, and S. Kim, "Wideband Wearable Antenna for Biomedical Telemetry Applications," in IEEE Access, vol. 8, pp. 15687-15694, 2020, doi: 10.1109/ACCESS.2020.2967413.

[17] T. W. Eigentler et al., "Wideband Self-Grounded Bow-Tie Antenna for Thermal MR," NMR in Biomedicine, vol. 33 , no. 5, p. e4274, May 2020, doi: $10.1002 / \mathrm{nbm} .4274$

[18] A. Darvazehban, S. A. Rezaeieh, and A. Abbosh, "Wideband and Compact Magneto-Electric Dipole Antenna for Electromagnetic Medical Imaging Systems," 2019 13th European Conference on Antennas and Propagation (EuCAP), 2019, pp. 1-3.

[19] B. M. Moloney, D. O’Loughlin, S. A. Elwahab, and M. J. Kerin, "Breast Cancer Detection-A Synopsis of Conventional Modalities and the Potential Role of Microwave Imaging," Diagnostics, vol. 10, no. 2, p. 103, February 2020, doi: 10.3390/diagnostics10020103.

[20] M. T. Islam, M. Z. Mahmud, M. Tarikul Islam, S. Kibria, and M. Samsuzzaman, "A Low Cost and Portable Microwave Imaging System for Breast Tumour Detection Using UWB Directional Antenna array," Scientific reports, vol. 9, no. 1, pp. 1-13, October 2019, doi: 10.1038/s41598-019-51620-z.

[21] K. Kishore, Antenna and Wave Propagation, Bangalore, New Delhi: I. K. International Publishing House Pvt. Ltd., 2009.

[22] B. Mohamadzade, R. B. V. B. Simorangkir, R. M. Hashmi, and A. Lalbakhsh, "A Conformal Ultrawideband Antenna With Monopole-Like Radiation Patterns," in IEEE Transactions on Antennas and Propagation, vol. 68, no. 8, pp. 6383-6388, August 2020, doi: 10.1109/TAP.2020.2969744.

[23] A. K. Patel, S. Yadav, A. K. Pandey, and R. Singh, "A wideband rectangular and circular ring-shaped patch antenna with gap coupled meandered parasitic elements for wireless applications," International Journal of RF and Microwave Computer-Aided Engineering, vol. 30, no. 1, p. e21992, January 2020, doi: 10.1002/mmce.21992.

[24] S. M. Abbas, S. C. Desai, K. P. Esselle, J. L. Volakis, and R. M. Hashmi, "Design and Characterization of a Flexible Wideband Antenna Using Polydimethylsiloxane Composite Substrate," International Journal of Antennas and Propagation, vol. 2018, pp. 1-6, 2018, doi: 10.1155/2018/4095765.

[25] M. A. Rahman, M. F. Hossain, M. A. Riheen, and P. K. Sekhar, "Early Brain Stroke Detection Using Flexible Monopole Antenna," Progress in Electromagnetics Research C, vol. 99, pp. 99-110, 2020, doi: 10.2528/PIERC19120704. 